\title{
Determination of hand grip strength and its correlates during pregnancy: a cross-sectional study
}

\author{
Auwal Abdullahi ${ }^{1,2^{*}}$, Amina Shuaib Bala ${ }^{1}$, Sani Musa Danazumi ${ }^{3}$, Saadatu Maiwada Abubakar ${ }^{1}$, \\ Rislanu Isyaku Adamu4 ${ }^{4}$, Steven Truijen², Musa Kani Zakari ${ }^{1}$, Christopher Olusanjo Akosile ${ }^{5}$, Wim Saeys ${ }^{2}$, \\ Isa Usman Lawal ${ }^{1}$, Mohammed Etoom ${ }^{6}$, Jibril Mohammed Nuhu' ${ }^{1}$, Mukadas Akindele Oyeniran ${ }^{1,7}$, \\ Kabir Isah Mayana ${ }^{1,8}$ and Ushotanefe Useh ${ }^{7}$
}

\begin{abstract}
Background: Pregnancy results in many changes, including reduced hand grip strength (HGS). However, good HGS is required for physical functions such as carrying and breastfeeding the baby after birth. The aim of this study was to determine the factors that may predict HGS during pregnancy.

Methods: The study was a cross-sectional study approved by the Research Ethics Committees of Kano State Ministry of Health and Aminu Kano Teaching Hospital in Kano, north-west, Nigeria. Pregnant women at the designated hospitals were included in the study if they had no serious comorbidities or any known neurological condition that affects the hands and the neck. Demographic characteristics and independent (predictor) variables (age, weight, height, BMI, maternity leave status, number of full-term deliveries, number of preterm deliveries, number of live births, number of abortuses, gravidity, trimester, systolic blood pressure, diastolic blood pressure, inter arm systolic BP difference [IASBP], inter arm diastolic BP difference [IADBP], and heart rate) of each of the participants were recorded by experienced therapists. The data were analysed using descriptive statistics, t-test, Pearson correlation coefficient and standard multiple regression.
\end{abstract}

Result: One hundred and sixty-one pregnant women with mean age, $25.04 \pm 4.83$ years participated in the study. In the dominant hand, 120 participants (74.5\%) had weak grip strength. In the non-dominant hand, 135 participants (83.9\%) had weak grip strength. For the dominant hand, the total variance explained by the whole model was significant, $28.5 \%, F(11,161)=1.187, R^{2}=0.081, p=0.300$. In the final model, none of the variables significantly predicted HGS. However, systolic blood pressure contributed to the model more than any other variable (Beta $=-0.155)$. For the non-dominant hand, the total variance explained by the whole model was not significant, $33.1 \%, F(11,161)=1.675$, $R^{2}=0.111, p=0.089$. In the final model, only systolic blood pressure (Beta $=-0.254, p=0.023$ ) significantly predicted hand grip strength.

Conclusion: Cardiovascular events or changes during pregnancy (such as change in systolic blood pressure) may be related to HGS in pregnant women. It is therefore, important for clinicians to pay attention to this, in planning rehabilitation strategies for pregnant women.

\footnotetext{
*Correspondence: aabdullahi.pth@buk.edu.ng

${ }^{1}$ Department of Physiotherapy, Bayero University, Kano, Nigeria

Full list of author information is available at the end of the article
} original author(s) and the source, provide a link to the Creative Commons licence, and indicate if changes were made. The images or other third party material in this article are included in the article's Creative Commons licence, unless indicated otherwise in a credit line to the material. If material is not included in the article's Creative Commons licence and your intended use is not permitted by statutory regulation or exceeds the permitted use, you will need to obtain permission directly from the copyright holder. To view a copy of this licence, visit http://creativecommons.org/licenses/by/4.0/. The Creative Commons Public Domain Dedication waiver (http://creativeco mmons.org/publicdomain/zero/1.0/) applies to the data made available in this article, unless otherwise stated in a credit line to the data. 
Keywords: Pregnancy, Blood pressure, Body mass index, Gravidity, Hand grip strength, Physical function, Breastfeeding, Activities of daily living

\section{Introduction}

Pregnancy can cause physiological, psychological and physical changes in women. Some of the physical changes include musculoskeletal changes such as reduced hand grip strength (HGS) [1, 2]. Reduced HGS during pregnancy is believed to be caused by several factors including hormonal changes (such as high level of circulating oestrogen), altered nutritional status and increased protein level (which may result in fluid retention in the body, including the wrist) $[3,4]$. In particular, a high level of circulating oestrogen and increased protein level can result in fluid retention, which occurs in up to $17 \%$ to $62 \%$ of pregnant women [3-6]. When there is fluid retention in the upper extremities, carpal tunnel syndrome in which the median nerve is compressed may result, which may in turn, result in reduced HGS $[3,7]$.

Reduced HGS may help indicate health outcomes. This is because hand grip strength is an indicator of many health outcomes such as physical strength, cognition, functional status, mobility, pulmonary function, and cardiovascular health $[2,8-11]$. Consequently, reduced HGS has been linked to poor muscle mass, decreased walking speed and physical activity level, as well as increased risk of death due to cardiovascular diseases $[9,12-16]$. In addition, HGS was reported to have a strong correlation with various anthropometric characteristics in both pregnant and non-pregnant women $[2,17,18]$. Furthermore, HGS can be affected by demographic factors such as age and gender [8]. Similarly, it may also be related to ethnicity and culture [19].

Reduced HGS is characterised by pain, numbness, difficulty in grasping objects, muscle weakness and tendency of things to drop from the hand [6, 20]. However, pregnant women require good HGS to carry out their daily living activities such as eating, washing, writing and grooming. Likewise, they require good hand grip strength to carry their babies, bathe and breastfeed them after giving birth. According Wade and Taylor, weakness of the upper extremity following delivery, such as in the idiopathic postpartum brachial neuritis, may result in difficulty in carrying out daily activities such as washing one's hair, pouring water from the jug and throwing a ball [21]. This report echoed the importance of upper limb function including HGS during pregnancy and after delivery. Unfortunately, routine check for HGS does not seem to be used during pregnancy in Kano, Nigeria. The aim of this study was to determine HGS and the factors that could predict it during pregnancy. In addition, the study aimed to look at the difference in HGS between trimesters. This is because knowing the status of HGS during pregnancy and the factors that could predict it can help clinicians in designing rehabilitation strategies to prevent or manage reduced HGS by addressing the predictors.

\section{Method}

The study used a cross-sectional research design. The population of the study was pregnant women attending antenatal clinics at Aminu Kano Teaching Hospital (AKTH), Murtala Muhammad Specialists Hospital (MMSH) and Muhammad Abdullahi Wase Specialist Hospital (MAWSH), all in Kano, Nigeria. The study was approved by the Research Ethics Committees of AKTH (AKTH/MAC/SUB/12A/P-3/VI/2392) and Kano State Ministry of Health (MOH/Off/797/T.I/740). Participants were included if they were pregnant (no age limit was considered because, in the environment where the data was collected, women get married before the age, 18), and had neither movement restriction in the upper limbs nor positive history of any neurological disorder. The participants were consecutively recruited into the study. In addition, all participants provided written informed consent for their participation in the study.

The minimum sample size for the study was 143 . This was calculated using $\mathrm{G}$ power software [22]. The calculation done was a priori for multiple linear regression, fixed-effect model. The parameters used were effect size $\left(\mathrm{f}^{2}\right)=0.15$ (moderate effect size, alpha value $=0.05$, power $=80 \%$ and number of predictors $=16$ (age, weight, height, BMI, maternity leave status, number of full-term deliveries, number of preterm deliveries, number of live births, number of abortuses, gravidity, trimester, systolic blood pressure, diastolic blood pressure, inter arm systolic BP difference [IASBP], inter arm diastolic BP difference [IADBP], and heart rate). We included maternity leave status as one of the independent variables because it may affect the participants' level of physical activity, which may also affect HGS. Data for this study was collected using a proforma for demographic and other independent variables, a portable weighing scale for body weight, tape measure $(60$ inches $/ 150 \mathrm{~cm}$, Shanghai, China) for height, Camry electronic hand dynamometer (EH101, United Kingdom) for HGS and sphygmomanometer, and stethoscope (Litman, USA) for blood 
pressure. An electronic hand dynamometer is an affordable and a reliable instrument for measuring of hand grip strength [23, 24].

Body weight was measured with the participants in minimal clothing and without shoes. The measurement was carried out in $\mathrm{kg}$ to the nearest $0.5 \mathrm{~kg}$ using a portable weighing scale [25]. Height was measured with the subjects standing erect and bare-footed against a calibrated wall with their feet together on a level floor. A horizontal ruler was rested on their heads, and the height was read from the wall [26]. The measurement was also carried out in centimetres to the nearest $0.5 \mathrm{~cm}$, and converted to meters thereafter. Body Mass Index (BMI) was calculated as weight in kilogram divided by height in meter squares [27]. BMI values were categorized as underweight $=\mathrm{BMI}$ below $18.5 \mathrm{~kg} / \mathrm{m}^{2}$, normal weight $=$ BMI from $18.5 \mathrm{~kg} /$ $\mathrm{m}^{2}$ to $24.9 \mathrm{~kg} / \mathrm{m}^{2}$, over weight $=$ BMI from $25 \mathrm{~kg} / \mathrm{m}^{2}$ to $29.9 \mathrm{~kg} / \mathrm{m}^{2}$ and obese $=$ BMI above $30.0 \mathrm{~kg} / \mathrm{m}^{2}$ [27].

For the measurement of HGS, the participants were seated comfortably in a chair with the arm resting on the arm rest. They were then made to hold the test arm of the dynamometer at a $90^{\circ}$ elbow flexion, with the forearm placed in a neutral position and the hand parallel to the forearm. Thereafter, the participants were asked to squeeze the dynamometer to the best of their ability three times. This was carried out for both hands starting with the dominant hand, followed by the non-dominant with two minutes interval between them. The measurements were recorded in kilograms and the mean of the three trials was taken as the measure of HGS. The three trials were carried out with each of the hands with one minute rest period between them.

Similarly, to measure blood pressure (BP), the participants were seated comfortably in a chair with the arm resting on the arm rest. The BP was measured using a mercury sphygmomanometer and was undertaken twice on each arm (for both the dominant and nondominant hands). One-minute interval was allowed between each measurement. We chose one minute interval because blood pressure can change with time. Therefore, we decided on a short interval. Following the measurements, the average was obtained and used as the BP value. All measurements were carried out in a conducive and well ventilated environment to avoid overestimating or underestimating the measurement since temperature can affect blood pressure. In addition, an appropriate cuff size was used, and the correct placement of the cuff was achieved (with lower edge of the cuff about 1 inch above elbow crease and the cuff's bladder over the brachial artery) in order to obtain accurate readings. The diaphragm of the stethoscope was placed over the brachial artery. The participants were

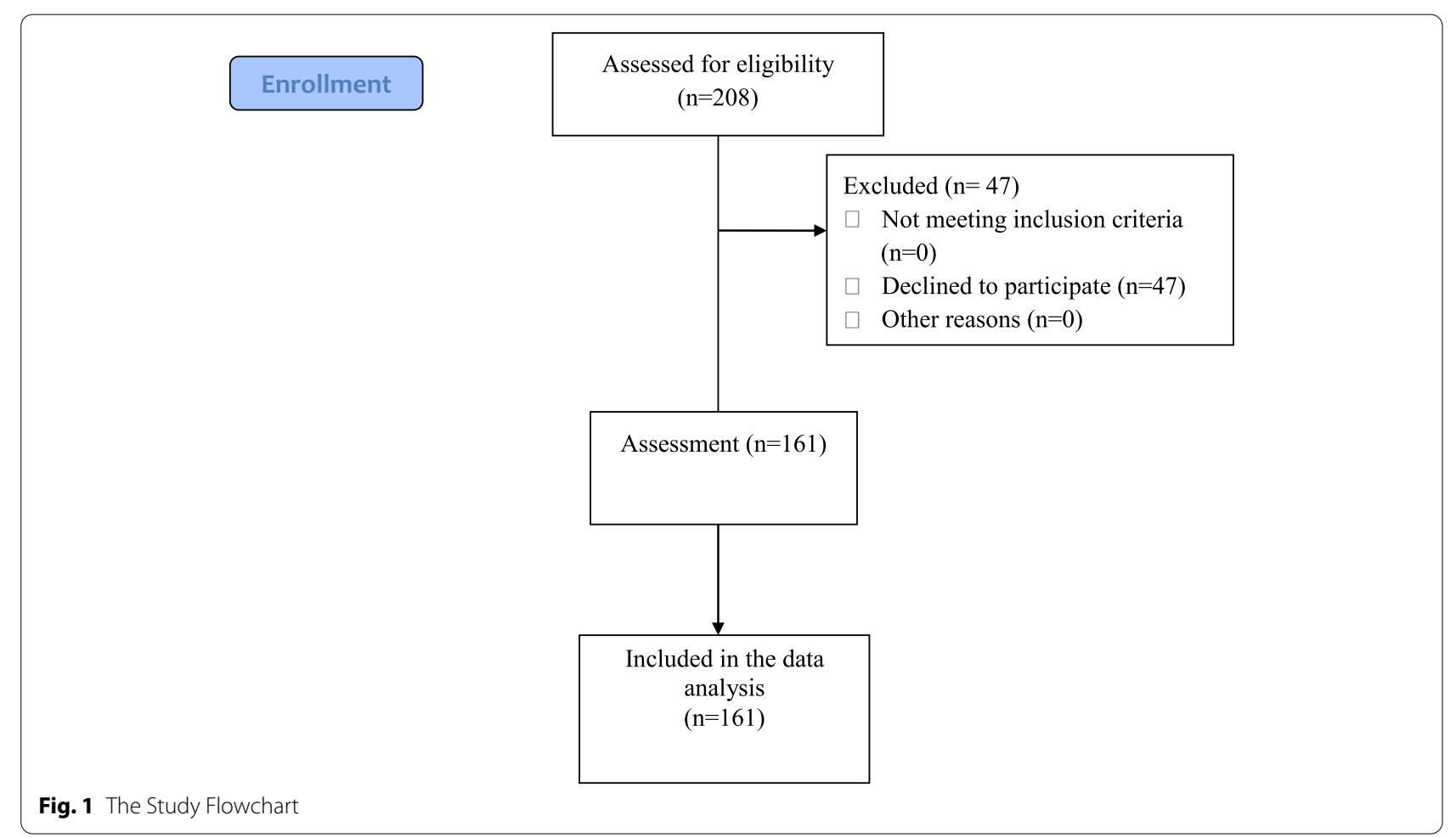


Table 1 Characteristics of the Study Participants $(n=161)$

\begin{tabular}{|c|c|c|c|}
\hline Variable & Mean \pm SD & Frequency & Percentage (\%) \\
\hline Age & $25.04 \pm 4.83$ years & & \\
\hline \multicolumn{4}{|l|}{ Age category } \\
\hline $17-22$ years & 55 & 34.2 & \\
\hline 23-28 years & 68 & 42.2 & \\
\hline 29-34 years & 30 & 18.6 & \\
\hline $35-40$ years & 8 & 5 & \\
\hline Weight & $62.38 \pm 11.53 \mathrm{~kg}$ & & \\
\hline Height & $2.49 \pm 12.02 \mathrm{~m}$ & & \\
\hline BMl & $26.28 \pm 5.12 \mathrm{~kg} / \mathrm{m}^{2}$ & & \\
\hline Ethnicity $Y / H / I / F / K$ & & $4 / 114 / 8 / 30 / 5$ & 2.5/70.8/5.0/18.6/3.1 \\
\hline Maternity leave Yes/No/NA & & $6 / 63 / 92$ & $3.7 / 39.1 / 57.1$ \\
\hline Occupation A/B/H/C/S & & $7 / 35 / 95 / 12 / 12$ & 4.3/21.7/59.0/7.5/7.5 \\
\hline Education N/P/S/T/None & & 9/11/91/49/1 & $5.6 / 6.8 / 56.5 / 30.4 / 6$ \\
\hline Socioeconomic L/M/H & & $4 / 156 / 1$ & $2.5 / 96.9 / 6$ \\
\hline Marital status S/M & & $3 / 158$ & $1.9 / 98.1$ \\
\hline Trimester 1st/2nd/3rd & & 19/50/92 & $11.8 / 31.1 / 57.1$ \\
\hline History of Hypertension Yes/No & & $18 / 143$ & $11.2 / 88.8$ \\
\hline Gravidity & $3.06 \pm 2.10$ & & \\
\hline SBP & $115.23 \pm 10.27 \mathrm{mmHg}$ & & \\
\hline DBP & $74.76 \pm 8.93 \mathrm{mmHg}$ & & \\
\hline ISBP & $4.59 \pm 5.51 \mathrm{mmHg}$ & & \\
\hline IDBP & $1.42 \pm 3.53 \mathrm{mmHg}$ & & \\
\hline Heart Rate & $83.86 \pm 12.03$ beats $/ \mathrm{min}$ & & \\
\hline HGS (d) & $20.46 \pm 4.61 \mathrm{~kg}$ & & \\
\hline HGS (nd) & $7.87 \pm 4.40 \mathrm{~kg}$ & & \\
\hline
\end{tabular}

KEY:*Y/H/I/F/K =Yoruba/Hausa/Igbo/Fulani/Kanuri, ${ }^{*} \mathrm{NA}=$ Not Applicable, ${ }^{*} \mathrm{~A} / \mathrm{B} / \mathrm{H} / \mathrm{C} / \mathrm{S}=$ Artisan/Business/House wife/Civil servant/Student, ${ }^{*} \mathrm{~N} / \mathrm{P} / \mathrm{S} / \mathrm{T} / \mathrm{None}=\mathrm{Non}-$ formal /Primary/Secondary/Tertiary/None, ${ }^{*} \mathrm{~L} / \mathrm{M} / \mathrm{H}=\mathrm{Low} /$ Middle/High, ${ }^{*} \mathrm{~S} / \mathrm{M}=$ Single/Married, ${ }^{*} \mathrm{SBP}=$ Systolic Blood Pressure, *DBP $=$ Diastolic Blood Pressure, ${ }^{*}$ IADSBP $=$ Inter Arm Difference in Systolic Blood Pressure, ${ }^{*}$ IADDBP = Inter Arm Difference in Diastolic Blood Pressure, *HGS (d) = Hand Grip Strength dominant, ${ }^{*}$ HGS (nd) = Hand Grip Strength non dominant

also instructed to relax and avoid any thought or activity that could raise their level of anxiety prior to the measurement. Data at the three study sites were collected by experienced physiotherapists (one in each study site) who were blinded from the aim of the study. The data collection took place between $4^{\text {th }}$ June, 2018 and $30^{\text {th }}$ August, 2018.

The data obtained were analysed using Statistical Package for Social Sciences (SPSS) version 20.0 and a p-value of $<0.05$ was considered significant in the analysis. The normality of the data distribution was assessed using Kolmogrov-Smirnov statistics which showed normal data distribution $(\mathrm{p}>0.05)$. Consequently, parametric statistics (Pearson product moment correlation) was used to analyse the relationship between the independent and dependent variables; and between the independent variables. In addition, the difference in HGS between trimesters was analysed using

Table 2 Differences in grip strength across trimesters $(n=161)$

\begin{tabular}{|c|c|c|c|c|c|}
\hline \multirow[t]{3}{*}{ Variable } & \multicolumn{3}{|l|}{ Trimester } & \multirow[b]{3}{*}{$\mathbf{F}$} & \multirow[b]{3}{*}{ P-value } \\
\hline & $\begin{array}{l}\text { First } \\
(n=19)\end{array}$ & $\begin{array}{l}\text { Second } \\
(n=50)\end{array}$ & $\begin{array}{l}\text { Third } \\
(n=92)\end{array}$ & & \\
\hline & \multicolumn{3}{|l|}{ Mean \pm SD } & & \\
\hline Dominant hand & $21.53 \pm 5.16$ & $20.22 \pm 4.24$ & $20.37 \pm 4.70$ & 0.596 & 0.552 \\
\hline Non-dominant hand & $19.77 \pm 3.58$ & $17.21 \pm 3.87$ & $17.84 \pm 4.73$ & 2.383 & 0.096 \\
\hline
\end{tabular}


Table 3 Relationship between dominant HGS with the clinical variable of the participants $(n=161)$

\begin{tabular}{llcl}
\hline $\begin{array}{l}\text { Dependent } \\
\text { variable }\end{array}$ & $\begin{array}{l}\text { Independent } \\
\text { variable }\end{array}$ & Correlation(r) & p-value \\
\hline Handgrip strength & Age & 0.128 & 0.106 \\
& Weight & 0.141 & 0.075 \\
& Height & 0.007 & 0.933 \\
& BMI & 0.006 & 0.943 \\
& Maternity leave & -0.116 & 0.142 \\
& Termed deliveries & 0.017 & 0.835 \\
& Pretermed deliver- & -0.023 & 0.775 \\
& ies & & \\
& Abortuses & -0.113 & 0.155 \\
& Livebirth & 0.036 & 0.652 \\
& Gravidity & 0.037 & 0.641 \\
& Trimester & -0.055 & 0.485 \\
& Systolic BP & 0.101 & 0.200 \\
& Diastolic BP & 0.053 & 0.508 \\
& IADSBP & 0.103 & 0.192 \\
IADDBP & 0.079 & 0.318 \\
Heart Rate & 0.070 & 0.376 \\
\hline
\end{tabular}

KEY: HGS Hand Grip Strength, BMI Body Mass Index, BP Blood pressure, IADSBP Inter Arm Difference in Systolic Blood Pressure, IADDBP Inter Arm Difference in Diastolic Blood Pressure

* Significant at $\mathrm{p} \leq 0.05$

Table 4 Relationship between non dominant HGS with the clinical variable of the participants $(n=161)$

\begin{tabular}{llcl}
\hline Dependent variable & $\begin{array}{l}\text { Independent } \\
\text { variable }\end{array}$ & Correlation(r) & p-value \\
\hline Handgrip strength & Age & 0.155 & 0.050 \\
& Weight & 0.110 & 0.165 \\
& Height & 0.028 & 0.725 \\
& BMI & 0.78 & 0.328 \\
& Maternity leave & -0.120 & 0.131 \\
& Termed deliveries & 0.014 & 0.855 \\
& Pretermed deliveries & -0.040 & 0.616 \\
& Abortuses & -0.138 & 0.081 \\
& Livebirth & 0.039 & 0.624 \\
& Gravidity & -0.046 & 0.559 \\
& Trimester & -0.080 & 0.314 \\
& Systolic BP & 0.137 & 0.082 \\
& IADSBP & 0.012 & 0.876 \\
& IADDBP & -0.004 & 0.963 \\
& Heart Rate & -0.029 & 0.712 \\
\hline
\end{tabular}

KEY: HGS Hand Grip Strength, BMI Body Mass Index, BP Blood pressure, IADSBP Inter Arm Difference in Systolic Blood Pressure, IADDBP Inter Arm Difference in Diastolic Blood Pressure

* Significant at $p \leq 0.05$ analysis of variance (ANOVA). The difference between trimesters was determined using ANOVA because the measurement was carried out once in each trimesters. Therefore, the rationale was to determine the variance between trimesters especially that there were differences in the number of participants between trimesters. Furthermore, descriptive statistics of mean, frequency, distribution tables, and standard deviation were used to describe the data.

Finally, standard multiple regression analysis was carried out to determine whether the independent variables age, BMI, maternity leave status, number of abortuses, number of live births, number of termed deliveries, number of preterm deliveries, trimester, heart rate, systolic BP, diastolic BP, inter arm systolic BP difference and inter arm diastolic BP difference could predict HGS in pregnant women. Standard multiple regression analysis means the independent variables were entered into the model to help determine the variable or variables that predict HGS better or more than the others without considering the order of entry of the variables into the model.

\section{Results}

A total of 161 pregnant women with age range, 17 to 39 years participated in the study (see Fig. 1 for the study flowchart). Details of the characteristics of the study participants are presented in Table 1.

In the dominant hand, 120 participants $(74.5 \%)$ had weak grip strength. In the non-dominant hand, 135 participants $(83.9 \%)$ had weak grip strength. Overall, the dominant and non-dominant hands' mean HGS was $20.46 \pm 4.61 \mathrm{~kg}$ and $7.87 \pm 4.40 \mathrm{~kg}$ respectively, indicating reduced grip strength. The normal values of HGS for the left and right hand are 30.8 (27.2 to 34.5) $\mathrm{kg}$ and 33.8 (29.5 to 38.1$) \mathrm{kg}$ respectively [28].

The result also showed no significant difference $(p>0.05)$ in grip strength between trimesters. The result is presented in Table 2.

For both the dominant and non-dominant hands, HGS is correlated with the independent variables. See Tables 3 and 4 for the dominant and non-dominant hands respectively. For the independent (predictor) variables, fullterm deliveries and live births $(r=0.936, p<0.001)$, and full-term deliveries and gravidity $(\mathrm{r}=0.930, \mathrm{p}<0.001)$ were highly correlated. See Table 5 for the details of the result of correlation analysis between the independent variables. Similarly, BMI is a variable gotten from the variables, weight and height. According to Pallant, when two independent variables are highly correlated $(r=0.9$ and above); or when an independent variable is a product of two different independent variables, such variables should be excluded from multiple regression analysis to 


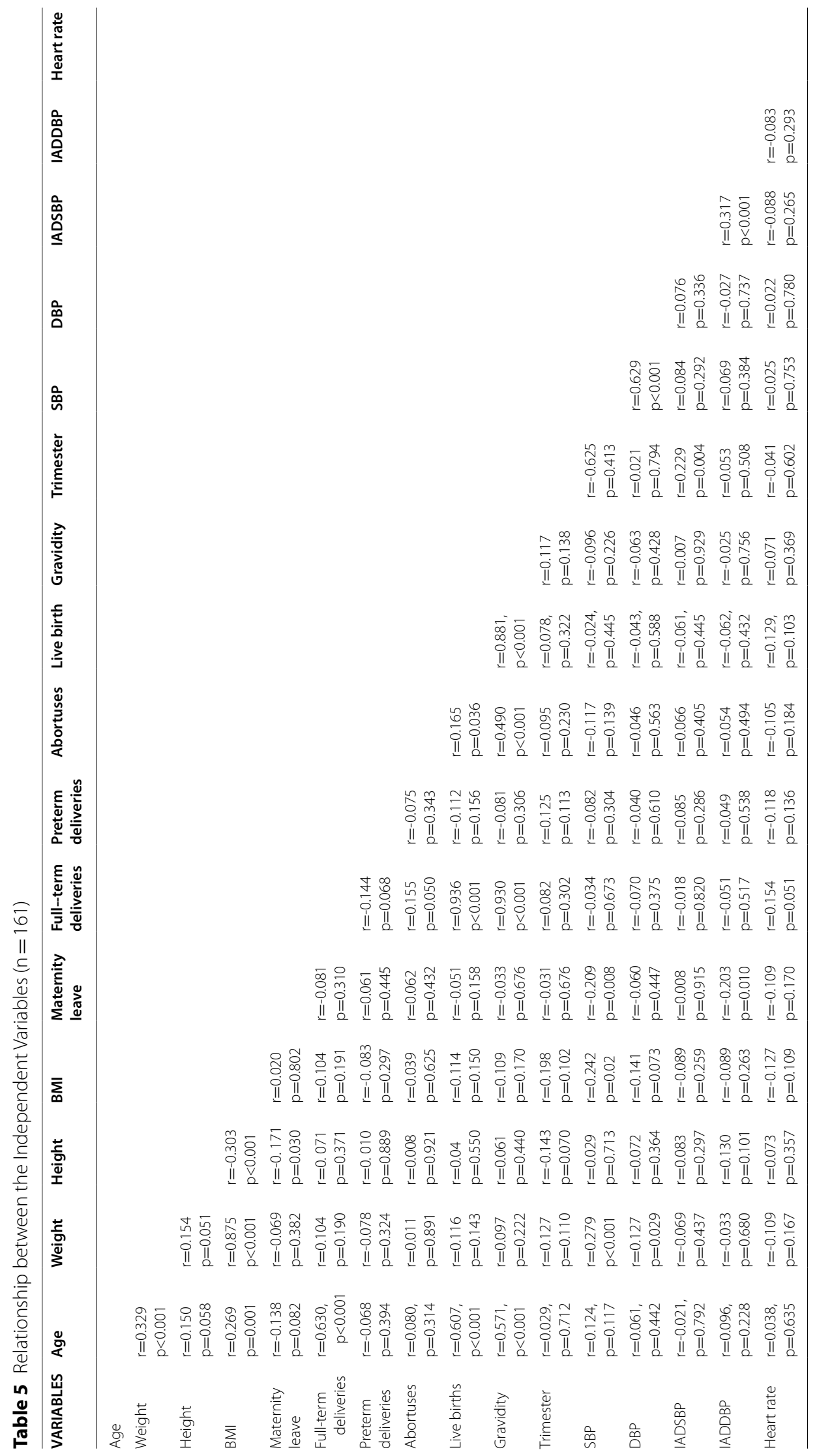


Table 6 Predictors of Hand Grip Strength in the dominant hand $(n=161)$

\begin{tabular}{lllll}
\hline Variables & $\mathbf{B}$ & $\mathbf{r}$ & $\mathbf{9 5 \%} \mathbf{C l}$ & $\boldsymbol{P}$-value \\
\hline Age & 0.129 & 0.129 & -0.030 to 0.288 & 0.112 \\
BMI & -0.049 & 0.005 & -0.207 to 0.109 & 0.540 \\
Maternity leave & -0.673 & -0.117 & -2.022 to 0.676 & 0.326 \\
Preterm deliveries & -0.591 & -0.023 & -5.342 to 4.160 & 0.806 \\
Abortuses & -0.582 & -0.113 & -1.475 to 0.310 & 0.199 \\
Trimester & -0.529 & -0.055 & -1.692 to 0.572 & 0.344 \\
SBP & 0.069 & 0.162 & -0.030 to 0.169 & 0.170 \\
DBP & -0.021 & 0.053 & -0.129 to 0.087 & 0.702 \\
IADSBP & 0.070 & 0.088 & 0.072 to 0.212 & 0.330 \\
IADDBP & -0.045 & 0.040 & -0.268 to 0.177 & 0.687 \\
Heart rate & -0.047 & -0.070 & -0.110 to 0.016 & 0.146 \\
\hline
\end{tabular}

$B M I$ Body Mass Index, SBP Systolic Blood pressure, DBP Diastolic Blood Pressure, IADSBP Inter Arm Difference in Systolic Blood Pressure, IADDBP Inter Arm Difference in Diastolic Blood Pressure

${ }^{*}$ Significant at $p \leq 0.05$

avoid violation of assumptions of multicollinearity and singularity respectively [29]. Consequently, the variables, full-termed deliveries, live births, gravidity, weight and height were removed from the analysis.

For the dominant hand, the total variance explained by the whole model was not significant, $28.5 \%, \mathrm{~F}(11$, $161)=1.187, R^{2}=0.081, p=0.300$. In the final model, none of the variables significantly predicted HGS. However, systolic blood pressure contributed to the model more than any other variable (Beta $=-0.155)$. See Table 6 and Fig. 2 for the details of this analysis.

For the non-dominant hand, the total variance explained by the whole model was not significant, $33.1 \%$, $F(11,161)=1.675, R^{2}=0.111, p=0.089$. In the final model, only systolic blood pressure $($ Beta $=-0.254$, $\mathrm{p}=0.023)$ significantly predicted hand grip strength. See Table 7 and Fig. 3 for the details of this analysis.

Although, there was no significant difference in HGS between trimesters, but majority of the participants $(\mathrm{n}=92)$ were within the $3^{\text {rd }}$ trimester. Therefore, we conducted a posthoc analysis to determine whether age, BMI, maternity leave status, number of preterm deliveries, number of abortuses, systolic blood pressure, diastolic blood pressure, inter arm systolic BP difference (IASBP), inter arm diastolic BP difference (IADBP), and heart rate will significantly predict HGS during the $3^{\text {rd }}$ trimester. The result showed that, for the dominant hand, the total variance explained by the whole model was not significant, $34.0 \%, F(10,92)=1.060, R^{2}=0.116$, $\mathrm{p}=0.402$. In the final model, only systolic blood pressure $($ Beta $=0.323, \mathrm{p}=0.034) \quad$ significantly predicted HGS. See Table 8 and Fig. 4 for the details of this analysis.

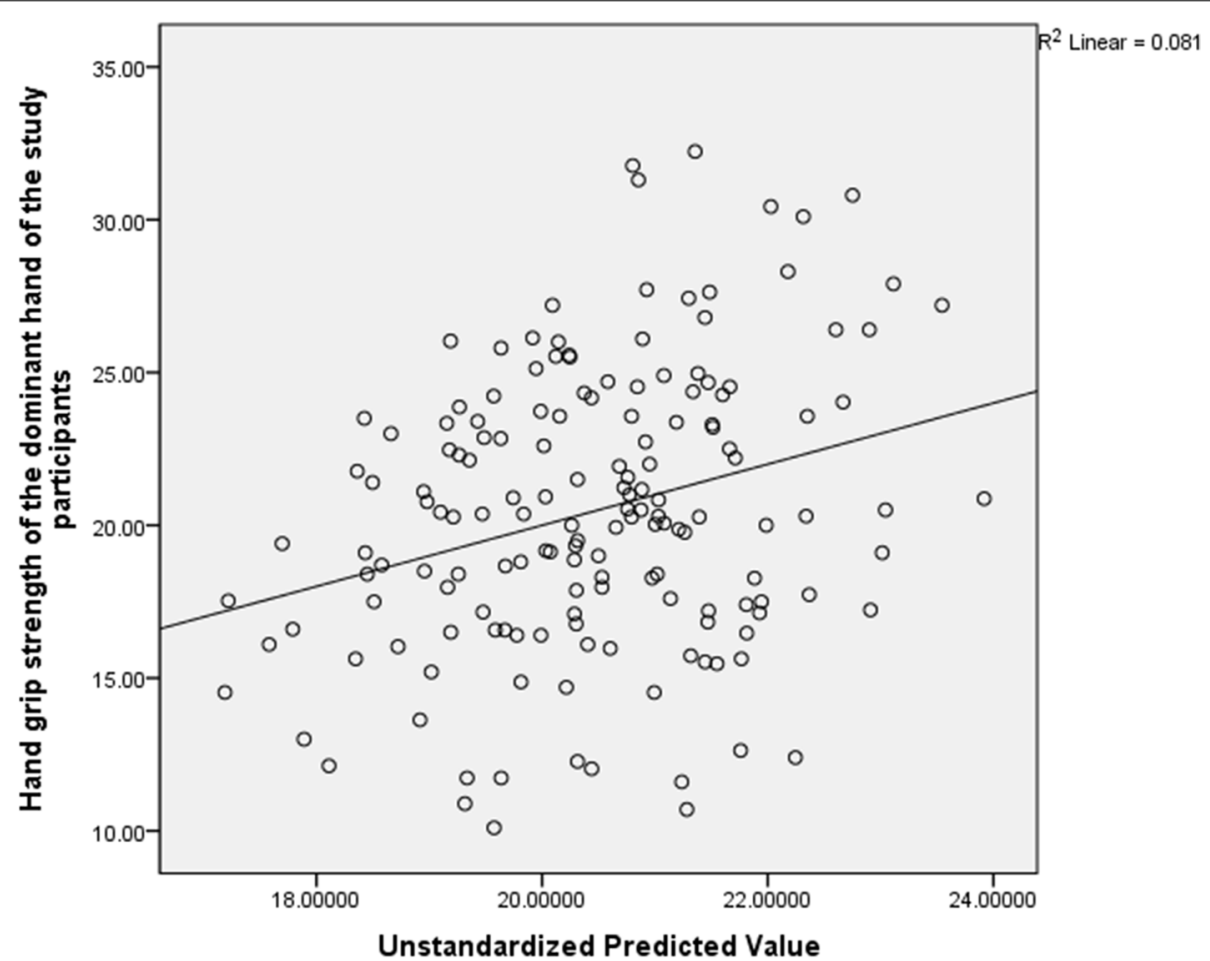

Fig. 2 Scatter Plot for the Predictors of Hand grip strength in the dominant hand indicating the regression line 
Table 7 Predictors of Hand Grip Strength in the non-dominant hand $(n=161)$

\begin{tabular}{lllll}
\hline Variables & B & r & 95\% Cl & $P$-value \\
\hline Age & 0.128 & 0.152 & -0.021 to 0.277 & 0.091 \\
BMI & 0.002 & 0.078 & -0.146 to 0.149 & 0.983 \\
Mater- & -0.662 & -0.120 & -1.924 to 0.600 & 0.302 \\
$\quad$ nity leave & & & & \\
Preterm deliv- & -0.219 & -0.040 & -4.678 to 4.239 & 0.923 \\
$\quad$ eries & & & & \\
Abortuses & -0.521 & -0.138 & -1.357 to 0.315 & 0.220 \\
Trimester & -0.173 & -0.080 & -1.741 to 0.316 & 0.173 \\
SBP & 0.109 & 0.191 & 0.016 to 0.202 & $0.023^{*}$ \\
DBP & -0.073 & 0.027 & -0.175 to 0.028 & 0.154 \\
IADSBP & -0.018 & -0.033 & -0.151 to 0.115 & 0.790 \\
IADDBP & -0.134 & -0.062 & -0.343 to 0.075 & 0.207 \\
Heart rate & -0.035 & -0.029 & -0.094 to 0.024 & 0.248 \\
\hline
\end{tabular}

$B M I$ Body Mass Index, SBP Systolic Blood pressure, DBP Diastolic Blood Pressure, $I A D S B P$ Inter Arm Difference in Systolic Blood Pressure, IADDBP Inter Arm Difference in Diastolic Blood Pressure

${ }^{*}$ Significant at $p \leq 0.05$

For the non-dominant hand, the total variance explained by the whole model was not significant, $34.1 \%, F(10,92)=1.068, R^{2}=0.116, p=0.396$. In the final model, none of the independent variables significantly predicted HGS. See Table 9 and Fig. 5 for the details of this analysis.

\section{Discussion}

The main aim of this study was to determine HGS and its predictors in pregnant women. The result of the study showed that only systolic blood pressure significantly predicted HGS. Both reduced grip strength and increased blood pressure have been reported to be caused by hormonal changes, increased protein level and fluid retention in pregnant women [2, 30,31]. One of the mechanisms of reduced HGS is carpal tunnel syndrome due to median nerve compression [3, 32]. However, aerobic exercise has been reported to normalise hormonal changes and protein level, and reduce fluid retention during pregnancy [33]. Even moderate to high intensity exercises are considered safe during normal pregnancies, and provide immense benefits for both maternal and foetal health such as maternal glycaemic control and uteroplacental and foetal blood flow, foetal growth, and increased muscle strength [34-38].

Similarly, it may help reduce fatigue and deconditioning during pregnancy and after delivery [39-41]. Therefore, it is important that pregnant women are prescribed regular aerobic exercise to help prevent or combat reduced HGS. This is because HGS and general strength of the upper limb are required for breastfeeding and caregiving of the baby after birth. In the absence of adequate hand grip and upper limb strength, these may not be possible, and the families may have to involve volunteer or paid

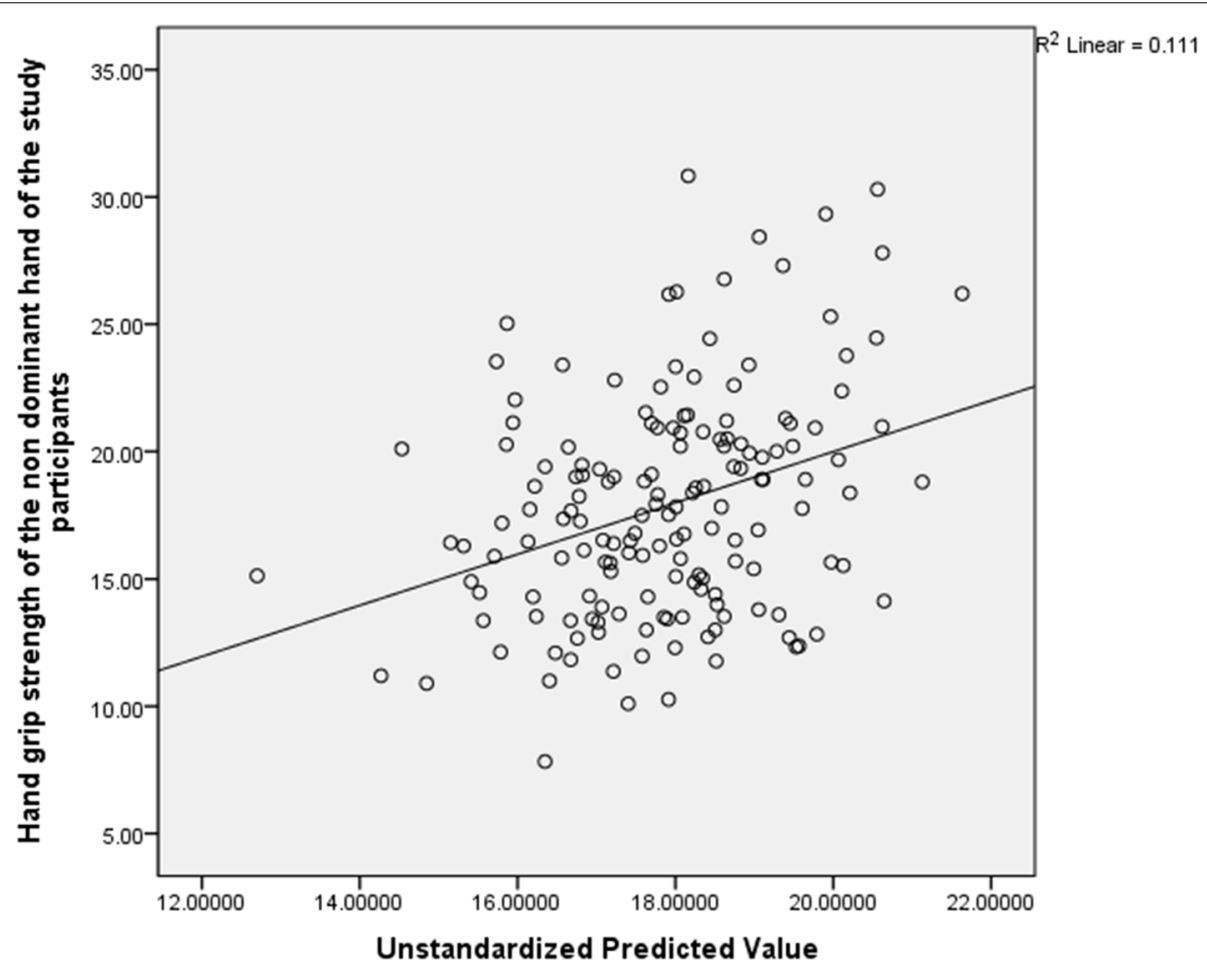

Fig. 3 Scatter Plot for the Predictors of Hand grip strength in the Non-dominant hand indicating the regression line 
Table 8 Predictors of Hand Grip Strength in the dominant hand for participants in the $3^{\text {rd }}$ trimester $(n=92)$

\begin{tabular}{lllll}
\hline Variables & B & \multicolumn{1}{l}{$\mathbf{r}$} & $\mathbf{9 5 \%} \mathbf{C l}$ & $\boldsymbol{P}$-value \\
\hline Age & 0.135 & 0.129 & -0.104 to 0.374 & 0.625 \\
BMI & -0.052 & 0.047 & -0.266 to 0.163 & 0.632 \\
Maternity leave & 0.020 & -0.095 & -1.767 to 2.079 & 0.983 \\
Preterm deliv- & -0.604 & -0.027 & -5.584 to 4.375 & 0.810 \\
$\quad$ eries & & & & \\
Abortuses & -0.637 & -0.152 & -1.770 to 0.496 & 0.267 \\
SBP & 0.148 & 0.207 & 0.011 to 0.286 & $0.034^{*}$ \\
DBP & -0.113 & -0.018 & -0.266 to 0.041 & 0.148 \\
IADSBP & 0.110 & 0.115 & -0.101 to 0.321 & 0.302 \\
IADDBP & -0.124 & 0.052 & -0.433 to 0.185 & 0.428 \\
Heart rate & -0.039 & -0.029 & -0.129 to 0.052 & 0.400
\end{tabular}

$B M I$ Body Mass Index, SBP Systolic Blood pressure, DBP Diastolic Blood Pressure, IADSBP Inter Arm Difference in Systolic Blood Pressure, IADDBP Inter Arm Difference in Diastolic Blood Pressure

* Significant at $p \leq 0.05$

caregivers. Considering how many times babies need to be breastfed per day, this can result in caregiver burden or huge financial loss on the volunteer caregiver and the paid caregiver allowance. However, strenuous exercises that can jeopardize the lives of the mother and the foetus such as a long jump should be avoided. In addition, if pregnant women developed reduced HGS that extended to after delivery, measures such as the use of adaptation pillow can be used to offer some support during breasting or holding the baby [42]. Upper limb functional activities such as opening jars and carrying bags during pregnancy could also help influence HGS. As such, these types of activities should be encouraged during pregnancy to help prevent reduced HGS.

In addition, in the present study, the result showed no significant difference in HGS between trimesters. However, in a recent study, it was reported that, weak grip strength was more prevalent in the third trimester [43]. This may not be unconnected to the fact that, during the third trimester, there is usually increased levels of hormones, especially oestrogen, which is implicated in the pathophysiology of reduced HGS $[1,44]$. Incidentally, most of the participants of the present study were within the third trimester of pregnancy. Therefore, one of the reasons for the difference could be because of the ethnic difference between the participants of the present study and the ones in the previous studies. Oestrogen level varies across ethnic groups [19]. Secondly, the participants in the present study $(25.04 \pm 4.83$ years) are younger as indicated by their mean age compared to the ones in the previous study ( $29.57 \pm 3.43$ years). Consequently, they might not have started experiencing a natural decline in HGS. According to Angst and colleagues, natural decline in HGS starts after the age 40 years [45].

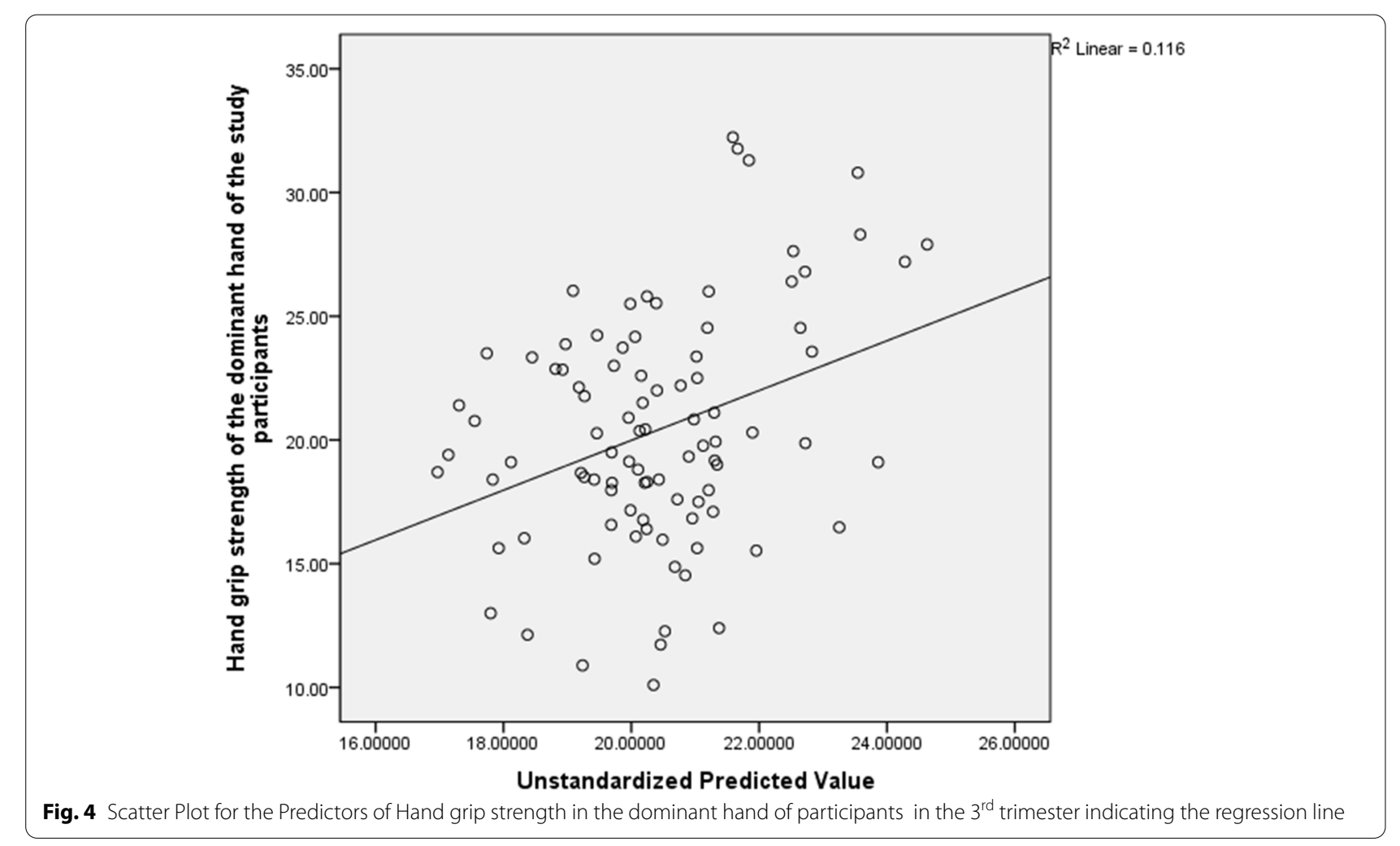


Table 9 Predictors of Hand grip strength in the non-dominant hand for participants in the $3^{\text {rd }}$ trimester $(n=92)$

\begin{tabular}{lllll}
\hline Variables & $\mathbf{B}$ & $\mathbf{r}$ & $\mathbf{9 5 \%} \mathbf{C l}$ & $\boldsymbol{P}$-value \\
\hline Age & 0.169 & 0.182 & -0.072 to 0.409 & 0.166 \\
BMI & -0.027 & 0.091 & -0.243 to 0.189 & 0.804 \\
Maternity leave & -0.376 & -0.131 & -2.255 to 1.503 & 0.692 \\
Preterm deliver- & -0.965 & -0.048 & -5.971 to 4.041 & 0.702 \\
$\quad$ ies & & & & \\
Abortuses & -0.724 & -0.152 & -1.863 to 0.415 & 0.210 \\
SBP & 0.114 & 0.217 & -0.024 to 0.252 & 0.105 \\
DBP & -0.054 & 0.051 & -0.208 to 1.00 & 0.489 \\
IADSBP 0.049 & 0.042 & -0.163 to 0.261 & 0.648 & \\
IADDBP & -0.106 & 0.054 & -0.417 to 0.206 & 0.502 \\
Heart rate & -0.063 & -0.079 & -0.155 to 0.028 & 0.170 \\
\hline
\end{tabular}

$B M I$ Body Mass Index, SBP Systolic Blood pressure, DBP Diastolic Blood Pressure, IADSBP Inter Arm Difference in Systolic Blood Pressure, IADDBP Inter Arm Difference in Diastolic Blood Pressure

* Significant at $p \leq 0.05$

This could explain why in the present study, there was no significant correlation between age and HGS. Thirdly, the lack of difference between trimesters could be due to an unequal number of participants in the three trimesters.

In a previous study, HGS was shown to have no significant association with blood pressure in the elderly; but it has a significant association with the middle-aged participants [46]. Although the aforementioned study was on apparently healthy individuals, the present study also found no significant correlation between HGS and blood pressure (both diastolic and systolic). Thus, age could be an important factor for HGS [45]. Interestingly, the present study found that systolic blood pressure is a statistically significant predictor of HGS among other clinical and socio-demographic variables in the non-dominant hand. However, when only the data of the participants in the $3^{\text {rd }}$ trimester was analysed, systolic blood pressure also significantly predicted HGS in the dominant hand . Long standing high systolic blood pressure could probably lead to inefficiency in the pumping of blood by the heart, which will ultimately lead to fluid retention. Fluid retention may worsen the pathophysiology of reduced HGS $[3,7]$. Additionally, heart rate increases when the heart has to pump blood with great effort [47]. Consequently, there was a negative and a weak, but non-significant correlation between heart rate and HGS in the present study. Thus, high blood pressure and increased heart rate may likely reduce HGS in pregnant women. In contrast, it was reported in studies on apparently healthy individuals that increased blood pressure is associated with increased HGS [14, 46]. The difference could be because, in pregnancy, hormonal changes also contribute to decrease in HGS [30].

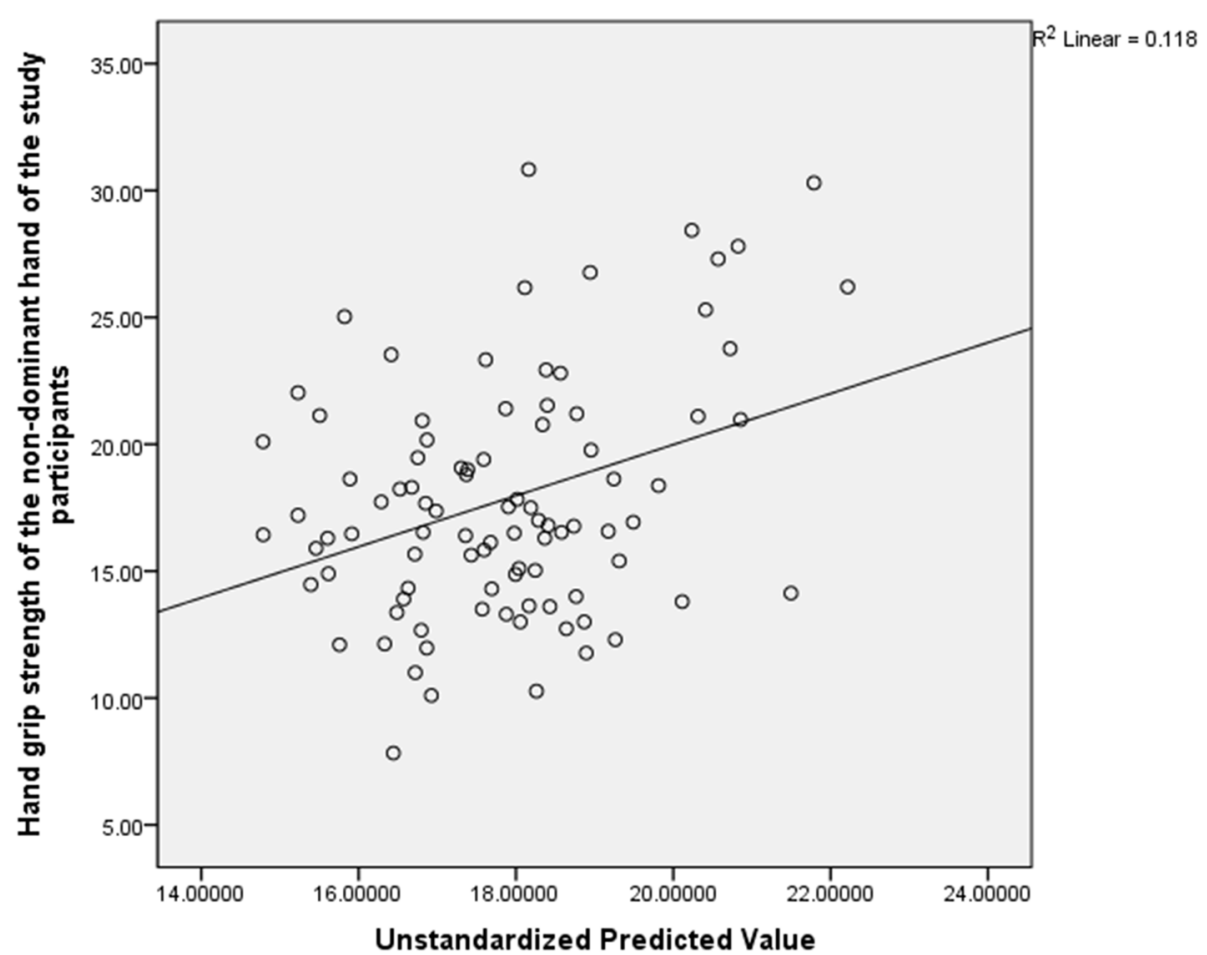

Fig. 5 Scatter Plot for the Predictors of Hand grip strength in the non-dominant hand of participants on the $3^{\text {rd }}$ trimester indicating the regression line 
Another variable in the literature that is related to HGS is BMI, and is said to exist regardless of hand dominance $[48,49]$. Similarly, in the present study, a strong but non-significant relationship between BMI and HGS in the non-dominant hand was found. When the BMI is high, it may also be associated with increased risk of high blood pressure [14]. According to the findings of this study, high blood pressure in particular, the systolic pressure is related to decrease in HGS. Therefore, those with high BMI may likely have reduced HGS. In addition, the higher the number of gravidity a woman had, and as she grows older, she might have increased level of oestrogen and decreased HGS[45]. Increased level of oestrogen is associated with reduced HGS [30]. Consequently, in the present study, gravidity was reported to have a weak positive but non-significant relationship with HGS which indicates that, the higher the gravidity, the more likely for pregnant women to have reduced HGS due to physical and physiological changes that result from pregnancy. Furthermore, it was stated that increased number of parity influences BMI which causes body adiposity [50, 51]. Level of adiposity also significantly influences HGS in females [2].

Full-term deliveries appear to be the best predictor of HGS even though it is not significant. This indicates that the more gravidity and the more pregnancy is to term, the more physiological changes occur in the body, leading to symptoms that cause reduced HGS. However, this study has some limitations or weaknesses. One of its weaknesses is the lack of use of qualitative inquiry to explore the pregnant women's experience with their HGS during pregnancy. In addition, lack of assessment of mobile phone use during pregnancy, and the level of physical activity of the study participants were some of the other potential weaknesses of this study. This is because, mobile phone usage, and physical activity level can affect HGS $[15,52]$. Moreover, the research design itself (crosssectional study) is also a potential limitation since the findings can only explain the relationship between the dependent and the independent variables, not cause and effect. Another additional limitation may be the lack of age-matched control and assessment of participants for carpal tunnel syndrome to actually confirm that the reduced HGS is due to pregnancy or related symptoms. In contrast, some of the strengths of this study are its relatively large sample size, and the provision of data from an ethnic, national or racial group not previously available and the possibility of highlighting it as a possible consideration for physical therapists and other professionals in medical rehabilitation in this environment.

\section{Conclusion}

Cardiovascular events or changes during pregnancy (such as change in systolic blood pressure) may be related to HGS in pregnant women. Therefore, it is important for clinicians to monitor pregnant women with reduced HGS for fluctuations in systolic blood pressure or viceversa. This will help them design novel exercises or rehabilitation strategies that can be used to combat the effects of reduced HGS and high blood pressure capable of endangering the lives of the expectant mother and the foetus or the baby after birth. In addition, future studies should determine how long post-delivery does it take for a person to regain HGS; and whether strength and conditioning exercise protocol is beneficial post-delivery.

\section{Supplementary Information}

The online version contains supplementary material available at https://doi. org/10.1186/s12884-021-04003-0.

Additional file 1.

Acknowledgements

We would like thank the patients who participated in the study and the therapists who helped in the collection of the data.

\section{Authors' contributions}

AA and ASB conceived the idea. AA, ASB, MSD, SAM, RIA, ST, MKZ, COA, WS, IUL, ME, JMN, MAO, KIM and UU, designed the study. AA and ASB monitored data collection. AA analyzed and interpreted the data. AA drafted the manuscript. ASB, MSD, SAM, RIA, ST, MKZ, COA, WS, IUL, ME, JMN, MAO, KIM and UU critically reviewed the drafted manuscript. All authors approved the manuscript for submission.

\section{Funding}

There was no funding for this study.

\section{Availability of data and materials}

The data for this study is available on request to the corresponding author

\section{Declarations}

\section{Ethics approval and consent to participate}

The study was approved by the Research Ethics Committees of AKTH (AKTH/ MAC/SUB/12A/P-3/VI/2392) and Kano State Ministry of Health (MOH/Off/797/ T.I/740). Also the study participants provided written informed consent to participate in the study. All methods were performed in accordance with Helsinki Declaration.

\section{Consent for publication}

Not applicable.

\section{Competing interests}

The authors declare no competing interest.

\section{Author details}

${ }^{1}$ Department of Physiotherapy, Bayero University, Kano, Nigeria. ${ }^{2}$ Department of Rehabilitation Sciences and Physiotherapy, University of Antwerp, Movant, Wilrijk, Belgium. ${ }^{3}$ Department of Physiotherapy, Federal Medical Center, Nguru, Yobe State, Nigeria. ${ }^{4}$ Department of Physiotherapy, University of Maiduguri Teaching Hospital, Maiduguri, Nigeria. ${ }^{5}$ Department of Medical Rehabilitation, Nnamdi Azikiwe University, Awka, Nigeria. ${ }^{6}$ Department of Physiotherapy, Aqba University of Technology, Aqaba, Jordan. ${ }^{7}$ Lifestyle Diseases Research 
Entity, Faculty of Health Sciences, North-West University, Potchefstroom, South Africa. ${ }^{8}$ Faculty of Health Sciences, University of Salford, Salford, UK.

\section{Received: 21 December 2020 Accepted: 12 July 2021} Published online: 04 August 2021

\section{References}

1. Soma-Pillay P, Nelson-Piercy C, Tolppanen H, Mebazaa A. Physiological changes in pregnancy. Cardiovasc J Afr. 2016;27(2):89-94. https://doi.org/ 10.5830/CVJA-2016-021.

2. Mbada CE, Adeyemi AB, Omosebi O, Olowokere AA, Faremi FA. Hand Grip Strength in Pregnant and Non-Pregnant Females. Middle East J Rehabil Health. 2015; 2(2). DOl: https://doi.org/10.17795/mejrh-27641

3. Mantle J, Haslam J, Barton S. Physiotherapy in Obstetrics \& Gynecology, 2nd edition. Elsevier publication. 40-43, 155-56.

4. Stachenfeld NS. Sex hormone effects on body fluid regulation. Exerc Sport Sci Rev. 2008;36(3):152-9. https://doi.org/10.1097/JES.0b013e3181 7 be928.

5. Bahrami MH, Rayegani SM, Fereidouni M, Baghbani M. Prevalence and severity of carpal tunnel syndrome (CTS) during pregnancy. Electromyography Clinical Neurophysiology. 2005;45(2):123-5.

6. Ablove RH, Ablove TS. Prevalence of carpal tunnel syndrome in pregnant women. Wincousin Medical Journal. 2009;108(4):194-6.

7. Alfonso C, Jann S, Massa R, Torreggiani A. Diagnosis, treatment and follow-up of the carpal tunnel syndrome: a review. Neurol Sci. 2010;31(3):243-52. https://doi.org/10.1007/s10072-009-0213-9.

8. Amaral CA, Amaral TLM, Monteiro GTR, Vasconcellos MTL, Portela MC. Hand grip strength: Reference values for adults and elderly people of Rio Branco, Acre, Brazil. PLoS ONE. 2019;14(1): e0211452. https://doi.org/10. 1371/journal.pone.0211452.

9. Rijk JM, Roos PR, Deckx L, van den Akker M, Buntinx F. Prognostic value of handgrip strength in people aged 60 years and older: a systematic review and meta-analysis. Geriatr Gerontol Int. 2016;16(1):5-20.

10. Beyer SE, Sanghvi MM, Aung N, Hosking A, Cooper JA, Paiva JM, et al. Prospective association between handgrip strength and cardiac structure and function in UK adults. PloS one. 2018;13(3):e0193124.

11. Savino E, Martini E, Lauretani F, Pioli G, Zagatti AM, Frondini C, et al. Handgrip strength predicts persistent walking recovery after hip fracture surgery. Am J Med. 2013;126(12):1068-75.

12. Leong P, Teo KK, Rangarajan S, Lopez-Jaramillo P, Avezum A, Orlandini $A$, et al. Prognostic value of grip strength: findings from the Prospective Urban Rural Epidemiology (PURE) study. Lancet. 2015;386(9990):266-73. https://doi.org/10.1016/S0140-6736(14)62000-6.

13. Prasitsiriphon O, Pothisiri W. Associations of Grip Strength and Change in Grip Strength With All-Cause and Cardiovascular Mortality in a European Older Population. Clin Med Insights Cardiol. 2018;12. doi:https://doi.org/ $10.1177 / 1179546818771894$

14. Ji C, Zheng $L$, Zhang R, Wu Q, Zhao Y. Handgrip strength is positively related to blood pressure and hypertension risk: results from the National Health and nutrition examination survey. Lipids Health Dis. 2018;17(1):86. https://doi.org/10.1186/s12944-018-0734-4.

15. Sekarsari S,Vitriana, Defi IR. Correlation between Handgrip Strength, Mobilization Function, Physical Activity Level, and Muscle Mass in Community-Dwelling Elderly in Bandung, West Java Province, Indonesia. International Journal of Integrated Health Sciences. 2018;6(1): 1-5. DOI: https://doi.org/10.15850/ijihs.v6n1.1047

16. Martin JC; Aguiar LT, Lara EM, Teixeira-Salmela LF, Faria CDCM. Assessment of grip strength with the modified sphygmomanometer test: association between upper limb global strength and motor function. Braz. J. Phys. Ther.2015; 19(6). https://doi.org/10.1590/bjpt-rbf.2014.0118

17. Kaur N, Koley S. An Association of Nutritional Status and Hand Grip Strength in Female Labourers of North India. Anthropologist. 2010;12(4):237-43.

18. Koley S, Atri R. A study on hand grip strength in pregnant and non pregnant women of north india. International journal of biomedical research. 2016; 236. Doi :https://doi.org/10.7439/ijbr

19. Kim C, Golden SH, Mather KJ, Laughlin GA, Kong S, Nan B, BarrettConnor E, et al. Racial/ethnic differences in sex hormone levels among postmenopausal women in the diabetes prevention program. J Clin
Endocrinol Metab. 2012;97(11):4051-60. https://doi.org/10.1210/jc. 2012-2117.

20. Rozali ZI, Noorman FM, De Cruz PK, Feng YK, Razab HWA, Sapuan J, Singh R \& Sikandhar FM., 2012. Impact of carpal tunnel syndrome on the expectant womwn'slife.AsiaPacificFamilyMedicine, 11:1 http/://www. apfmj.com/content/11/1/1

21. Wade J, Taylor T. Postpartum Idiopathic Brachial Neuritis in a Sport Medicine Physician. J Brachial Plex Peripher Nerve Inj. 2015;10(1):e50-e52. Published 2015 Jul 24. doi:https://doi.org/10.1055/s-0035-1558424

22. Faul F, Erdfelder E, Lang A-G, Buchner A. G*Power 3: A flexible statistical power analysis program for the social, behavioral, and biomedical sciences. Behav Res Methods. 2007;39:175-91.

23. Hogrel J-Y. Grip strength measured by high precision dynamometer in healthy subjects 5 to 80 years. BMC Musculoskeletal Disorders. 2015; 16(139). doi: https://doi.org/10.1186/3/289-015-0612-4.

24. Keep H, Luu L, Berson A, Garland SJ. Validity of the Handheld Dynamometer Compared with an Isokinetic Dynamometer in Measuring Peak Hip Extension Strength. Physiother Can. 2016;68(1):15-22. https://doi.org/10. 3138/ptc.2014-62.

25. Rezende FAC, Rosado LEFPL, Franceschinni SCC, Rosado GP, Ribeiro RCL. Avaliação da aplicabilidade de fórmulas preditivas de peso eestatura em homens adultos. Rev Nutr. 2009 ;22(4): 443-51.

26. Shrivastava SR, Shrivastava PS, Ramasamy J. Assessment of nutritional status in the community and clinical settings. J Med Sci. 2014:34:211-3.

27. World Health Organization (WHO) Resolution WHA57.17. Global strategy on diet, physical activity and health 57th World Health Assembly resolutions and decisions, annexes. Geneva: WHO; 2004. 17-22 May 2004

28. Bohannon RW, Peolsson A, Massy-Westropp N, Desrosiers J, BearLehman J. Reference values for adult grip strength measured with a Jamar dynamometer: a descriptive meta-analysis. Physiotherapy. 2006;92(1):11-5.

29. Pallant J. SPSS survival manual : a step by step guide to data analysis using SPSS ( $4^{\text {th }}$ ed). Maidenhead : Open University Press/McGraw-Hill, 2010

30. Abduljalil KK, Furness PP, Johnson TN, Rostami-Hodjegan AA, Soltani $\mathrm{HH}$. Anatomical, physiological and metabolic changes with gestational age during normal pregnancy: a database for parameters required in physiologically based pharmacokinetic modelling. Clin Pharmacolkinet. 2012;51:365-96.

31. Anderson GD. Pregnancy-induced changes in pharmacokinetics: a mechanistic-based approach. Clin Pharmacokinet. 2005:44:989-1008.

32. Wright $C$, Smith B, Wright S, Weiner M, Wright K, Rubin D. Who develops carpal tunnel syndrome during pregnancy: An analysis of obesity, gestational weight gain, and parity. Obstetric Med. 2014;7(2):90-4. https://doi. org/10.1177/1753495X14523407.

33. Prather $H$, Tracy Spitznagle T, Hunt D, MD. Benefits of Exercise During Pregnancy. 2012. PM\&R 4(11):845-50. DOl:https://doi.org/10.1016/j.pmrj. 2012.07.012

34. Hinman SK, Smith KB, Quillen DM, Smith MS. Exercise in Pregnancy: A Clinical Review. Sports Health. 2015;7(6):527-31. https://doi.org/10.1177/ 1941738115599358.

35. de Barros MC, Lopes MA, Francisco RP, Sapienza AD, Zugaib M. Resistance exercise and glycemic control in women with gestation diabetes mellitus. Am J Obstet Gynecol. 2010;203:556.e1-e6.

36. de Oliveria Melo AS, Silva JL, Tavares JS, Barros VO, Leite DF, Amorim MM. Effect of a physical exercise program during pregnancy on uteroplacental and fetal blood flow and fetal growth: a randomized controlled trial. Obstet Gynecol. 2012;120:301-10.

37. Denison HJ, Syddall HE, Dodds R, et al. Effects of aerobic exercise on muscle strength and physical performance in community-dwelling older people from the Hertfordshire cohort study: a randomized controlled trial. J Am Geriatr Soc. 2013;61(6):1034-6. https://doi.org/10.1111/ jgs.12286.

38. Baena-García L, Coll-Risco I, Ocón-Hernández O, et al. Association of objectively measured physical fitness during pregnancy with maternal and neonatal outcomes. The GESTAFIT Project [published correction appears in PLoS One. 2020 Apr 1;15(4):e0231230]. PLoS One. 2020;15(2):e0229079.doi:https://doi.org/10.1371/journal.pone. 0229079 
39. Artal R, O'Toole M. Guidelines of the american college of obstetricians and gynecologists for exercise during pregnancy and the postpartum period. Br J Sports Med. 2003;37:6-12.

40. Foxcroft KF, Rowlands IJ, Byrne NM, Mclntyre HD, Callaway LK. Exercise in obese pregnant women: The role of social factors, lifestyle and pregnancy symptoms. BMC Pregnancy Childbirth. 2011;11:4.

41. Poudevigne MS, OConnor PJ. A review of physical activity patterns in pregnant women and their relationship to psychological health. Sports Med. 2006;36:19-38.

42. Sri Widiastuti IAK, Rustina Y, Efendi D. The use of breastfeeding pillow to reduce discomfort for breastfeeding mothers. Pediatr Rep. 2020;12(Suppl 1):8702. Published 2020 Jun 25. doi:https://doi.org/10.4081/pr.2020.8702

43. Żelaźniewicz A, Pawłowski B. Maternal hand grip strength in pregnancy, newborn sex and birth weight. Early Hum Dev. 2018;119:51-5. https:// doi.org/10.1016/j.earlhumdev.2018.03.004

44. Schock, H., Zeleniuch-Jacquotte, A., Lundin, E. et al. Hormone concentrations throughout uncomplicated pregnancies: a longitudinal study. BMC Pregnancy Childbirth. 2016; 16(146). https://doi.org/10.1186/ s12884-016-0937-5

45. Angst F, Drerup S, Werle S, Herren DB, Simmen BR, Goldhahn J. Prediction of grip and key pinch strength in 978 healthy subjects. BMC Musculoskelet Disord. 2010;19(11):94. https://doi.org/10.1186/1471-2474-11-94.

46. Taekema DG, Gussekloo J, Maier AB, Westendorp RG, de Craen AJ. Handgrip strength as a predictor of functional, psychological and social health. A prospective population-based study among the oldest old. Age Ageing. 2010;39(3):331-7. doi: https://doi.org/10.1093/ageing/afq022
47. Duncker DJ, Bache RJ. Regulation of Coronary Blood Flow During Exercise. Physiol Rev. 2008;88:1009-86. https://doi.org/10.1152/physrev. 00045.2006.

48. Diez-Fernandez A, Sanchez-Lopez M, Gullias-Gonzalez R, Notario-Pacheco B, Canete Garcia-Parieto J, Arias-Palencia N, et al. BMI as a mediator of relationship between muscular fitness \& cardiometabolic: A meta analysis. Plus One. 2015. https://doi.org/10.1371/jp.0116506.

49. Dong B, Wang Z, Arnold L, Song Y, Wang HJ, Ma J. The association between blood pressure and gripstrength in adolescents. Hypertension Res. 2016;39:919-25. https://doi.org/10.1038/hr.2016.84.

50. Koch E, Bogado M, Araya F, Romero T, Diaz C, Manriquez L, et al. Impact of parity on anthropometric measures of obesity controlling by multiple confounders: a cross-sectional study in Chilean women. J Community Health. 2008;62(5):461-70.

51. Gunderson EP. Childbearing and obesity in women: weight before, during, and after pregnancy. Obstet Gynecol Clin North Am. 2009;36(2):317-32.

52. Osailan A. The relationship between smartphone usage duration (using smartphone's ability to monitor screen time) with hand-grip and pinch-grip strength among young people: an observational study. BMC Musculoskeletal Disorders. https://doi.org/10.1186/s12891-021-04054-6

\section{Publisher's Note}

Springer Nature remains neutral with regard to jurisdictional claims in published maps and institutional affiliations.
Ready to submit your research? Choose BMC and benefit from:

- fast, convenient online submission

- thorough peer review by experienced researchers in your field

- rapid publication on acceptance

- support for research data, including large and complex data types

- gold Open Access which fosters wider collaboration and increased citations

- maximum visibility for your research: over $100 \mathrm{M}$ website views per year

At BMC, research is always in progress.

Learn more biomedcentral.com/submissions 